\title{
Toxicity of tetrabromobisphenol A (TBBPA) in zebrafish (Danio rerio) in a partial life-cycle test
}

\author{
R. V. Kuiper ${ }^{1}$, E. J. van den Brandhof ${ }^{2}$, P. E. G. Leonards ${ }^{3,4}$, L. T. M. van der $\operatorname{Ven}^{2}$, \\ P. W. Wester ${ }^{2}$ and J. G. Vos ${ }^{1,2}$
}

(1) Department of Pathobiology, Faculty of Veterinary Medicine, Utrecht University, Yalelaan 1, P.O. Box 80158, 3508 TD Utrecht NL, The Netherlands

(2) National Institute of Public Health and the Environment (RIVM), Anthonie van

Leeuwenhoeklaan 9, P.O. Box 1, 3720 BA Bilthoven, The Netherlands

(3) Netherlands Institute for Fisheries Research (RIVO), Haringkade 1, P.O. Box 68, 1970 AB IJmuiden, The Netherlands

(4) Present address: Institute for Environmental Studies (IVM), Vrije Universiteit Amsterdam, De Boelelaan 1087, 1081 HV Amsterdam, The Netherlands

Email: R.V.Kuiper@vet.uu.nl

\begin{abstract}
Toxicological effects of the widely used flame retardant, tetrabromobisphenol A (TBBPA) were assessed in a partial life-cycle test with zebrafish (Danio rerio). Exposure of adult fish during 30 days to water-borne TBBPA in nominal concentrations ranging from 0 (control) to $1.5 \mu \mathrm{M}$ was followed by exposure of the offspring in early life stages up to 47 days posthatching (dph) to the same concentrations. Adults exposed to 3 and $6 \mu \mathrm{M}$ showed severe disorientation and lethargy shortly after beginning of exposure and were euthanized. Because semistatic exposure resulted in fluctuating water concentrations, pooled fish samples were chemically analyzed for internal dose assessment. Egg production was decreased in fish exposed to TBBPA concentrations of $0.047 \mu \mathrm{M}$ and higher, and a critical effect level of $7.2 \mu \mathrm{g} / \mathrm{g}$ lipid with a lower $5 \%$ confidence limit of $3.9 \mu \mathrm{g} / \mathrm{g}$ lipid for $50 \%$ decreased egg production was calculated. Histology of adult ovaries indicated a relative increase of premature oocytes in two surviving females exposed to $1.5 \mu \mathrm{M}$. Hatching of TBBPA-exposed larvae was decreased except in animals exposed to $0.375 \mu \mathrm{M}$. In the highest exposure concentration, early posthatching mortality was high (81\%) in larvae and the surviving juveniles showed a significant predominance of the female phenotype. Exposure of eggs from control parents up to $6 \mu \mathrm{M}$ TBBPA resulted in increasing malformation and pericardial fluid accumulation from $1.5 \mu \mathrm{M}$; at higher concentrations, all embryos failed to hatch. The presented results indicate decreased reproductive success in zebrafish at environmentally relevant TBBPA concentrations.
\end{abstract}

\section{Introduction}

Tetrabromobisphenol A [2,2-bis-(3,5-dibromo-4-hydroxyphenyl)-propane; TBBPA] is today's most abundantly used brominated flame retardant (BFR). Annual consumption of TBBPA in Europe alone was $7.800 \mathrm{t}$ in 2002, representing $6 \%$ of the total global use (BSEF 2004). TBBPA is applied in a wide variety of consumer products. Its predominant use (e.g., in circuitry boards) is as reactive flame retardant, i.e., the flame retardant is covalently bound to the polymer. However, approximately $10 \%$ is used as an additive flame retardant in a wide variety of consumer products including housings of domestic electric/electronic appliances (BSEF 2004), facilitating the release of TBBPA into the environment (Birnbaum and Staskal 2004). The TBBPA may leach from landfills (Osako et al. 2004), and consequently end up in surface waters. As a result, TBBPA has been found in aquatic sediment samples from all over the world (Sellström and Jansson 1995; Watanabe and Sakai 2003; Morris et al. 2004) and although usually below the limit of detection in the water phase, TBBPA has repeatedly been detected in fish (Asplund et al. 1999; Morris et al. 2004; Ohta et al. 2004) in levels up to $63 \mathrm{ng} / \mathrm{g}$ lipid weight in eel from freshwater and up to $245 \mathrm{ng} / \mathrm{g}$ lipid in whiting (muscle) from the North Sea (Morris et al. 2004); recently, $583 \mathrm{ng}$ TBBPA/g lipid was detected in a pooled sample of 13 sand eel from the Waddensea (RIVO 2003; unpublished data). 
In fish, TBBPA is acutely toxic at high concentrations as shown in a number of studies. $\mathrm{LC}_{50}$ concentrations reported include $0.51 \mathrm{mg} / \mathrm{l}(0.9 \mu \mathrm{M})$ in bluegill sunfish, $0.40 \mathrm{mg} / \mathrm{l}(0.7 \mu \mathrm{M})$ in rainbow trout (WHO/IPCS 1995), and a relatively high $3 \mathrm{mg} / \mathrm{l}(5.5 \mu \mathrm{M})$ in zebrafish (Lee et al. 1993). Evidence for TBBPA toxicity at lower doses is limited and points to modulation of the thyroid and reproductive hormonal systems: TBBPA competes with the in vitro binding of thyroxin to its human plasma-transporter protein, transthyretin (Meerts et al. 2000; Hamers et al. 2004), and the rat thyroid receptor (Kitamura et al. 2002), and increases the response to T3 in cultured GH3 rat pituitary adenoma cells (Kitamura et al. 2005a). However, $10^{-8} \mathrm{M}$ (54 ng/l) TBBPA and higher may suppress T3-dependent tail shortening in Rana rugosa tadpoles, indicating anti-thyroid activity (Kitamura et al. 2005b).

Cultured MCF-7 breast cancer cells show a weak estrogenic response to TBBPA (Körner et al. 1998; Olsen et al. 2003), and TBBPA inhibits in vitro estradiol sulfonation (Hamers et al. 2004), indicating potential for both direct and indirect estrogenic activity in vivo. Increased uterus weights in ovariectomized mice exposed to TBBPA for 3 days $(20 \mathrm{mg} / \mathrm{kg} /$ day, intraperitoneal) confirm estrogenicity in vivo (Kitamura et al. 2005a).

Since sex steroids and thyroid hormones influence reproduction in aquatic vertebrates and may interact during larval development (Cyr and Eales 1996; Arcand-Hoy and Benson 1998), the presence of TBBPA in aquatic environments raises concern as to their possible impact on reproductive health in fish. Regarding endocrine effects of TBBPA in fish, the focus has been on the estrogen-dependent production of the yolk precursor vitellogenin (VTG), which was not affected by intraperitoneal exposure to TBBPA in rainbow trout and eelpout (Christiansen et al. 2000; Ronisz et al. 2004); however the combined effects of possible disruption of estrogen or thyroid hormonal systems on ecologically relevant parameters like reproduction and early life-stage development in fish exposed to TBBPA have not been taken into account.

In the present study, zebrafish (Danio rerio) were exposed to TBBPA in a partial life-cycle test using a benchmark approach to further investigate possible ecotoxicological consequences. Egg production and fertilization ratio were used to monitor reproduction, and development and mortality were investigated in offspring until juvenile stage (47 days posthatch). Whole body sections of both adults and offspring were examined histologically with special attention for reproductive and endocrine target organs. TBBPA concentrations were determined in water and fish (adult and juvenile) for accurate dose-response assessment.

\section{Materials and methods}

The TBBPA (99.17\% pure, containing TBBPA and o,p'-TBBPA as impurities; HPLC-analyzed) was obtained as a composite mix of technical products from various producers through BSEF (kindly provided by Dr. Klaus Rothenbacher).

\section{Exposure of adults}

Adult reproductive zebrafish ( $D$. rerio) were supplied by a commercial importer (Ruinemans Aquarium BV, Montfoort, The Netherlands) and kept under quarantine conditions for a minimum period of 4 weeks. About 7 days prior to testing, the animals were transferred to the test system containing standard formulated water (Van der Ven et al. 2006). Each group was kept in 6 I water in an all-glass aquarium, covered by a glass plate. Water was continuously aerated via glass tubes and water temperature was maintained at $27 \pm 2^{\circ} \mathrm{C}, \mathrm{pH}$ ranged from 7.2 to 8.4 and oxygen levels were $>5 \mathrm{mg} / \mathrm{l}$ at all times. Nitrate levels were checked before each renewal and were usually below $0.5 \mathrm{mg} / \mathrm{l}$, never exceeding $0.8 \mathrm{mg} / \mathrm{l}$. A daily cycle of $14 \mathrm{~h}$ light, $10 \mathrm{~h}$ dark was maintained.

Adults were exposed to water-borne TBBPA during 30 days using dimethyl sulfoxide (DMSO, Acros, 's Hertogenbosch, The Netherlands) as solvent (final DMSO concentration: $0.01 \%$ in all groups including controls). A benchmark-dosing regimen was applied using nominal concentrations of 0 (control), $0.023,0.047,0.094,0.188,0.375,0.750,1.50,3.00$, and $6.00 \mu \mathrm{M}$ (Table 1) in a single experimental unit per test concentration consisting of three 
males and three females, except for the control group, which was in duplicate. Animals were fed defrosted Artemia (Landman BV, Hoevelaken, The Netherlands) twice a day in an amount that was consumed completely within $5 \mathrm{~min}$. Males were kept separate from females inside a nylon mesh net (mesh size: $3 \mathrm{~mm}$ ). Exposure was semi static by medium renewal every 34 days. At the end of week 4 , water samples were collected in clean glassware immediately after renewal $(0 \mathrm{~h})$, and immediately before the end of exposure in week 5 ( $96 \mathrm{~h}$ later). Water samples were also collected from two aquariums under identical conditions, but without fish, at 0,72 , and $96 \mathrm{~h}$ after renewal. Water samples were stored at $-20^{\circ} \mathrm{C}$ until chemical analysis.

Table 1 Internal tetrabromobisphenol A (TBBPA) concentrations in male and female adult zebrafish

\begin{tabular}{|c|c|c|c|c|}
\hline \multirow{3}{*}{$\begin{array}{l}\text { Dose } \\
\text { Nominal water concentration }(\mu \mathrm{M} \text { TBBPA) }\end{array}$} & \multicolumn{4}{|c|}{ Result (measurements in single fish) } \\
\hline & \multicolumn{4}{|c|}{ TBBPA (ng/g ww) TBBPA (ng/g lw) } \\
\hline & Male & Female & Male & Female \\
\hline Control-A & $<11$ & $<6.3$ & $<262$ & $<166$ \\
\hline Control-B & $<11$ & $<7.7$ & $<262$ & $<175$ \\
\hline $0.023 \mu \mathrm{M}$ & 120 & 190 & 3,871 & 6,129 \\
\hline $0.047 \mu \mathrm{M}$ & 590 & 1,500 & 16,857 & 30,612 \\
\hline $0.094 \mu \mathrm{M}$ & 2,300 & NA & 71,875 & NA \\
\hline $0.188 \mu \mathrm{M}$ & 1,800 & 9,800 & 36,735 & 376,923 \\
\hline $0.375 \mu \mathrm{M}$ & 4,000 & 3,900 & 114,286 & 59,091 \\
\hline $0.75 \mu \mathrm{M}$ & 9,100 & 6,200 & 178,431 & 193,750 \\
\hline $1.5 \mu \mathrm{M}$ & 12,000 & 23,000 & 285,714 & 489,362 \\
\hline
\end{tabular}

$w w$ wet weight, I $w$ lipid weight, $N A$ not analyzed, and $<$ (number) below limit of detection

With both sexes placed inside the nylon mesh for $24 \mathrm{~h}$, reproduction was monitored 1 day after each water renewal; then clutch size, fertilization ratio, and hatching were determined. During exposure, the animals were monitored daily for (abnormal) behavior or disease, and mortality. After 30 days, the adults were euthanized in $100 \mathrm{mg}$ tricaine methanesulphonate/L (MS222, Sigma-Aldrich, Zwijndrecht, the Netherlands) buffered with $500 \mathrm{mg} \mathrm{NaHCO} / 3$, and length and weight were determined, from which a condition factor (CF; weight/length ${ }^{3}$ ) was derived. From each group, one male and female were rinsed with water and dipped dry before freezing and storage at $-20^{\circ} \mathrm{C}$ for chemical analysis; the remaining animals were fixed in Bouin's fixative, and after $24 \mathrm{~h}$ transferred to $70 \%$ ethanol until histological processing.

\section{Exposure of juveniles}

During weeks 4 and 5 of adult exposure, replicate groups of 50 fertilized eggs each (or less when not available) were randomly selected per dose and placed in $10-\mathrm{cm}$ diameter glass petri dishes containing $60 \mathrm{ml}$ DSW with the same nominal TBBPA concentrations as their parents. Hatching was recorded with a target number of $2 \times 50$ larvae sampled for continued exposure by semi-static renewal (twice weekly). From 1 to 14 days posthatching (dph), the larvae were fed with fresh rotifer suspension (Branchionus rubens) daily. Starting at $7 \mathrm{dph}$, the larvae were fed with newly hatched Artemia nauplii two times a day (suspension adjusted to $17 \%$ dry matter, starting with $5 \mu \mathrm{l}$ per larva, increasing to $120 \mu \mathrm{l}$ per juvenile at $46 \mathrm{dph}$ ). At $15 \mathrm{dph}$, the animals were transferred to all-glass aquariums under similar conditions as described for adults, containing $1.5 \mathrm{I}$ water per 50 animals; this volume was increased to $3 \mathrm{I}$ at $21 \mathrm{dph}$. Water samples were collected during week 5 of juvenile exposure from one control group and dose groups $0.094,0.375$, and $1.5 \mu \mathrm{M}$ TBBPA directly after renewal $(t=0)$ and $72 \mathrm{~h}$ later $(t=72)$, and stored at $-20^{\circ} \mathrm{C}$ for chemical analysis. On $46 \mathrm{dph}$, feeding was discontinued and animals were euthanized on day 47 posthatching. Larvae were monitored for abnormal behavior and growth, malformations, and survival. Juveniles were euthanized in buffered MS222, and length and weight were determined. Four animals per replicate were rinsed in clean water, dipped dry, frozen and stored at $-20^{\circ} \mathrm{C}$ for chemical analysis (TBBPA body burden). Remaining animals were fixed in Bouin's for histological processing. 
In addition, eggs from control parents were exposed for 3 days using 96-well plates (Greiner, Alphen a/d Rijn, the Netherlands). Fertilized eggs were individually placed in round-bottom wells containing $200 \mu \mathrm{l}$ of DSW with $0,0.094,0.188,0.375,0.75,1.5,3.0$, and $6.0 \mu \mathrm{M}$ TBBPA. About 12 eggs per concentration were randomly assigned to the plate; concentrations were also randomized. Development and survival in vivo was monitored three times a day using an inverted microscope. The procedure was carried out in duplicate.

The present study was approved of by the Ethical Committee for Animal Welfare in Experiments of RIVM and complies with Dutch legislation.

\section{Histological processing and evaluation}

After routine tissue processing and paraffin embedding, whole-body serial sections $(4 \mu \mathrm{M})$ were cut at approximately $40 \mu \mathrm{M}$ intervals from all adults except those sampled for chemical analysis, and a randomly chosen sub-sample of on average 30 juveniles per concentration group, including cross sections through gonads and thyroid. Sections were stained with hematoxylin/eosin (H \& E) and evaluated in random order by two independent observers.

\section{Chemical analysis of fish and water samples}

Total body analysis was performed on all frozen samples. Per adult concentration group, one male and one female were analyzed individually. Because of small size, four juvenile fish from each concentration group were pooled. Fish were thawed and dried with $\mathrm{NaSO}_{4}$, and stored for $2 \mathrm{~h}$. The dried sample was extracted with a Soxhlet apparatus using hexane: acetone $(3: 1$, $\mathrm{v} / \mathrm{v}$, Promochem, Wesel, Germany). An internal standard (1 ml of $200 \mathrm{ng} / \mathrm{ml}$ 13C-TBBPA, CIL, Andover, MA, USA) was added to the extract, which was subsequently evaporated to $10 \mathrm{ml}$. An aliquot of the extract was dried with nitrogen and the lipid content was gravimetrically determined. The residual extract was acidified $(\mathrm{pH}=2)$, and sulfuric acid was added to remove the lipids. The cleaned extract was further purified with silica gel using isooctane and isooctane: diethyl ether (85:15, v/v, Promochem) as eluents. Finally, the silica eluate was evaporated to dryness with nitrogen, and $1 \mathrm{ml}$ of methanol was added. The TBBPA was determined with LC-MS/MS (LCQ Advantage, Thermo Finnigan, San Jose, CA, USA) using electrospray ionization. Identification of TBBPA was based on the bromine cluster at $\mathrm{m} / \mathrm{z} 444$ 452, and for quantification, the daughter ion $\mathrm{m} / \mathrm{z} 447$ of the parent molecular ion $(\mathrm{m} / \mathrm{z} 543)$ was used. A Zorbax, Eclipse XDB-C18 column was used with a gradient of ammonium chloride $(0.1 \mathrm{mM})$ and acetonitrile (ACN) starting from 0 to $6 \mathrm{~min}$. at ammonium chloride: ACN (3:1, v/v); followed by ammonium chloride: $\operatorname{ACN}(1: 9, \mathrm{v} / \mathrm{v})$ from 6 to $10 \mathrm{~min}$.

Water samples were analyzed in duplicate. An aliquot of the samples was taken, and $1 \mathrm{ml}$ of $200 \mathrm{ng} / \mathrm{ml}$ 13C-TBBPA was added as an internal standard. After the water was acidified $(\mathrm{pH}=2)$ and hexane was added, it was shaken for $2 \mathrm{~min}$. The organic layer was separated. This procedure was repeated twice to ensure complete extraction of the water sample. The combined hexane extract was evaporated to dryness and methanol was added. The TBBPA was determined with LC-MS/MS.

\section{Statistics}

Continuous data were explored by Analysis of Variance (ANOVA) and linear regression, using SPSS 12.0.1 Software (SPSS Inc., Chicago, USA). Kruskall-Wallis and Fisher's exact tests (SPSS 12.0.1) were used for the analysis of non-parametric entities.. Geometrical means of the successive clutch sizes (eggs produced per group when reproduction was successful) were used to compare the egg production between groups; this is because within groups, these observations were not independent. A fitted dose-response model (PROAST software, RIVM, Bilthoven, The Netherlands, Slob 2002) was used to calculate the concentration leading to a $50 \%$ reduction in clutch size, together with a lower $5 \%$ confidence limit for that concentration. 


\section{Results}

\section{Exposure of adults}

\section{Chemical analysis}

Results from chemical analysis of adult fish are shown in Table 1. The TBBPA levels in animals, determined on both wet, and lipid-weight basis, showed a strong linear relation with the nominal water concentration (linear regression: $R^{2}=0.80$ and 0.65 , respectively); correction for lipid content did not change regression statistics significantly; TBBPA content was not related to gender. Less then $1 \%$ of the total amount of TBBPA added was found in the animals after 30 days of exposure. Water concentrations immediately after renewal were $96 \pm 11 \%$ (SD) of the nominal concentrations. During the exposure cycles, water-TBBPA concentrations dropped and reached a minimum after $96 \mathrm{~h}$ at $5.2 \pm 2.7 \%$ (SD) of the nominal values; a gradual decrease was measured at 24,72 , and $96 \mathrm{~h}$ after renewal in a pilot study (data not shown). The TBBPA levels in aquariums without fish decreased to 71 and $61 \%$ of the initial levels after 72 and $96 \mathrm{~h}$, respectively.

\section{General parameters}

During adult exposure, abnormal behavior was noted within $1 \mathrm{~h}$ from the start of the experiment, in animals exposed to 3.0 and $6.0 \mu \mathrm{M}$ TBBPA, starting with slow-down of swimming and reduced respiration, followed by progressive loss of equilibrium. After a few hours, these animals were recumbent on the bottom of the tank and were euthanized for ethical reasons, and fixated for histological processing only; water samples were not collected. Apart from these euthanized animals, there was no exposure-related morbidity or mortality. No dose-dependent differences in weight, length or CF were noted in either sex.

\section{Reproduction and hatching}

Although, the number of eggs produced per group on days when reproduction was monitored was variable throughout the experiment and between concentration groups, the total number of eggs produced by all groups exposed to TBBPA was lower than the number produced by each control group (Fig. 1). There was substantial variation in the number of clutches produced with a relatively high number in adults at $1.5 \mu \mathrm{M}$ TBBPA (Fig. 1). Average clutch size showed a more consistent dose response and was well below 200 eggs/clutch (three females) from $0.047 \mu \mathrm{M}$ TBBPA onwards. A fitted dose-response model using internal concentrations calculated $50 \%$ reduction of clutch size (geometric mean) at an internal concentration of $7.2 \mu \mathrm{g} \mathrm{TBBPA} / \mathrm{g}$ lipid with a lower $95 \%$ confidence limit of $3.9 \mu \mathrm{g} / \mathrm{g}$ lipid (Fig. 2). Egg-fertilization ratio was not affected by TBBPA (Fig. 3). Hatching of embryos from exposed eggs was decreased, except in embryos exposed to $0.375 \mu \mathrm{M}$ TBBPA (Table 2), which hampers interpretation of dose-response characteristics.

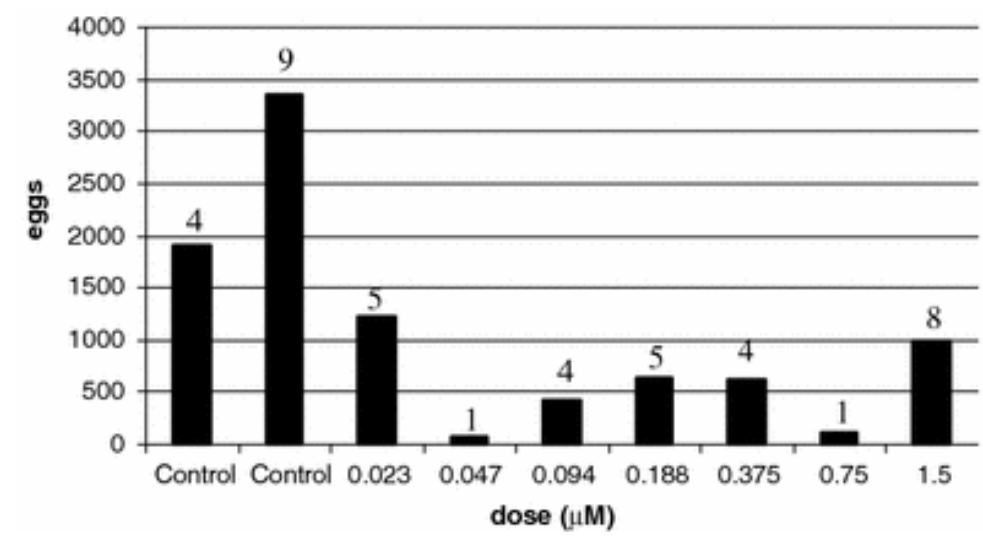

Fig. 1 Total egg production in zebrafish resulting from during 30 days exposure of adults. Numbers above bars represent number of clutches (three females combined) 


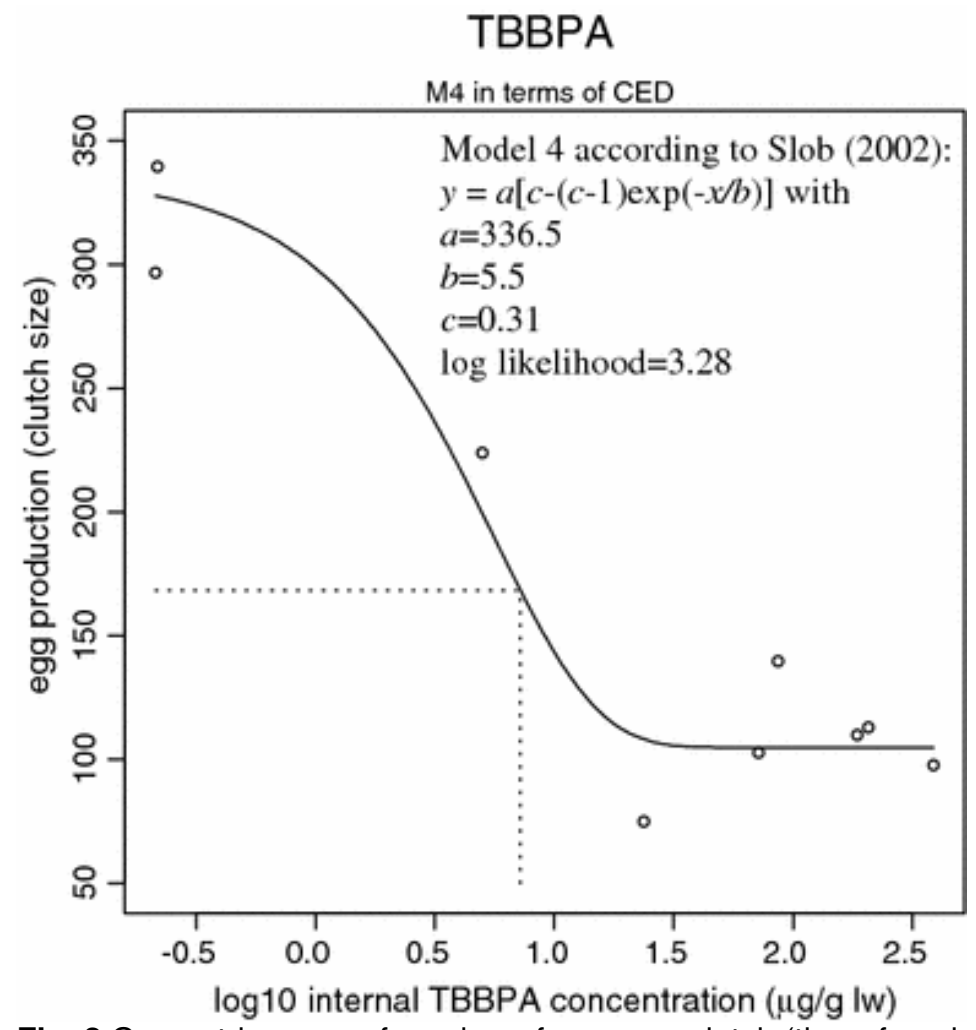

Fig. 2 Geometric mean of number of eggs per clutch (three females combined) as a function of tetrabromobisphenol A (TBBPA) concentration, with fitted dose-response model. A $50 \%$ reduction was estimated at a critical internal level of $7.2 \mu \mathrm{g} / \mathrm{g}$ lipid weight (dashed lines)

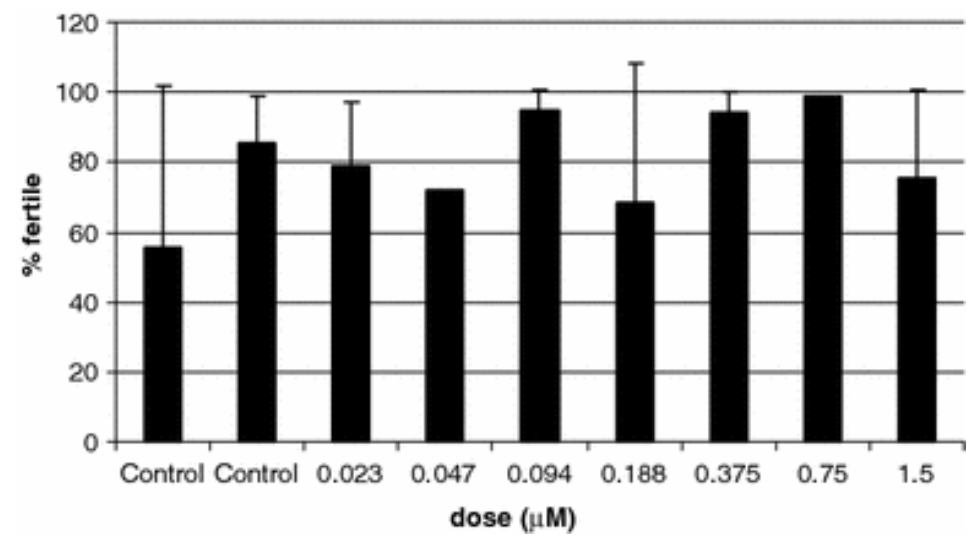

Fig. 3 Fertilization ratios in eggs from zebrafish exposed to TBBPA; egg deposition was in the exposure medium. Error bars represent standard deviations of fertilization ratios from successive clutches 
Table 2 Hatching of embryos from adults during week 4 of exposure, and survival of hatched juveniles after the first week of exposure to tetrabromobisphenol A (TBBPA)

$\begin{array}{llll}\begin{array}{l}\text { Nominal water concentration } \\ (\boldsymbol{\mu} \text { M TBBPA) }\end{array} & \begin{array}{l}\text { Eggs sampled during } \\ \text { week } 4\end{array} & \begin{array}{l}\text { Hatching } \\ (\%)\end{array} & \begin{array}{l}\text { Posthatch } \\ \text { survival (\%) }\end{array} \\ 0 & 600 & 79.7 & 97 \\ 0.023 & 100 & 43.0^{*} & 98 \\ 0.047 & 54 & 33.3^{*} & \text { NA } \\ 0.094 & 164 & 20.1^{*} & 100 \\ 0.188 & 300 & 13.0^{*} & \text { NA } \\ 0.375 & 369 & 80.0 & 96 \\ 1.5 & 315 & 58.1^{*} & 19^{*}\end{array}$

NA not applicable

*Significantly decreased compared to controls (Fisher's exact test: $P<0.01$ )

\section{Adult histology}

Whole-body histological sections revealed an increased estimated area occupied by previtellogenic oocytes in both microsopically analyzed females that had been exposed to $1.5 \mu \mathrm{M}$ TBBPA during 30 days; this condition was seen in one out of the four control females and did not occur in the intermediate dose groups (Fig. 4). Early atresia of oocytes characterized by hypertrophy and vacuolization of surrounding granulosa cells, hyalinization and fragmentation of the zona radiata, and disruption of yolk vesicles, were observed in females from all groups (35\% overall prevalence), and was slightly less frequent (one out of four; not statistically significant) in the control groups. No dose-related changes were found in male gonads. Thyroid tissue appeared similar throughout all groups, showing variably sized colloid containing follicles lined by cubic epithelial cells, interpreted as moderately active. Without exception, female livers stained more strongly basophilic than male livers; differences in staining intensity were not dose related. Fragmentation of chromatin (karyorrhexis) in renal tubular epithelium was observed in $76 \%$ of the females but not in males, and was not related to TBBPA dose. The acute behavioral effects in animals exposed to $3.0 \mu \mathrm{M}$ TBBPA and higher were not accompanied by histopathological changes.

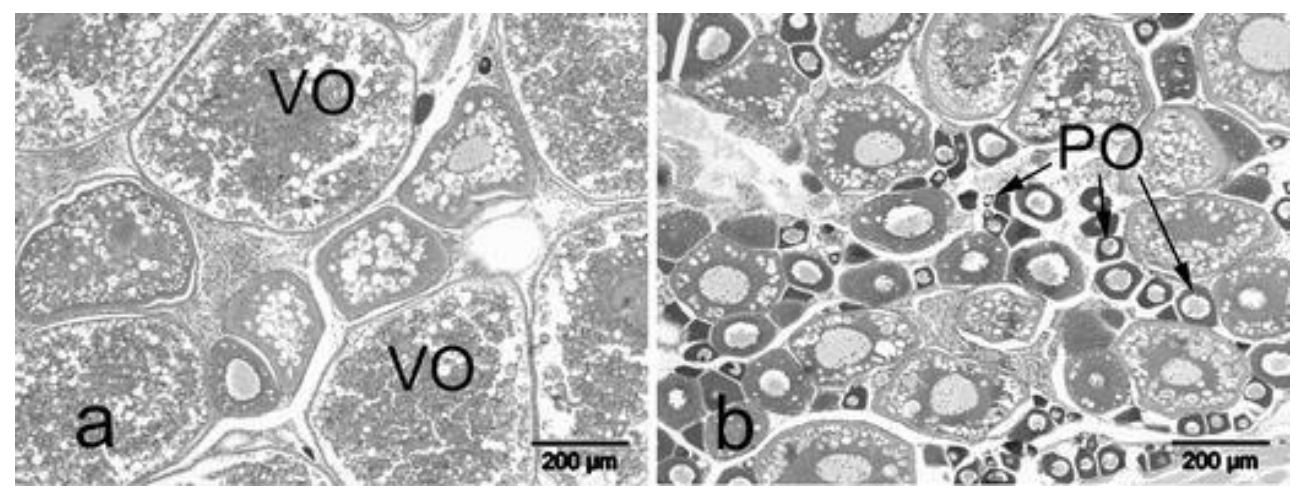

Fig. 4 Ovary of control (a) and exposed (1.5 $\mu \mathrm{M}$ TBBPA; $\mathbf{b})$ zebrafish. Note the relative increase of the smaller, non-granulated previtellogenic oocytes in the exposed ovary. VO vitellogenic oocytes, PO previtelogenic oocytes 


\section{Exposure of juveniles}

\section{Chemical analysis}

In juvenile zebrafish, TBBPA levels ranged from below the detection limit to $5.6 \mu \mathrm{g} / \mathrm{g}$ lipid in animals exposed to a nominal dose of $1.5 \mu \mathrm{M}$.

The TBBPA levels in exposure water directly after renewal were $80 \pm 16 \%$ (SD) of the nominal dose. After $72 \mathrm{~h}$, levels had dropped to $22 \pm 6 \%$ (SD) of the nominal dose. Water was not analyzed at $96 \mathrm{~h}$ after renewal.

\section{Juvenile growth, development, and survival}

Juveniles from dose groups $0,0.023,0.094,0.375$, and $1.5 \mu \mathrm{M}$ were exposed to similar nominal concentrations as their parents until $47 \mathrm{dph}$; in adult dose groups $0.047,0.188$, and $0.75 \mu \mathrm{M}$, egg production during the last week of adult exposure was insufficient for subsequent exposure of offspring. Hatching ratios were significantly reduced in all exposed groups except when exposed to $0.375 \mu \mathrm{M}$ (Table 2); a dose-response relation was not observed. Whereas at lower doses, posthatching mortality was low, at $1.5 \mu \mathrm{M} 81 \%$ of all larvae died during the first week of exposure (Table 2). Mortality was preceded by retardation of development (smaller animals, no swim-up even after $72 \mathrm{~h}$ posthatching) and malformations (abnormally curved spines, accumulation of clear fluid in the pericardial region and body cavity). Larvae at lower exposure levels showed no malformations and no effects on length, weight or $\mathrm{CF}$ at the end of the exposure period were noted. Exposure of eggs from untreated parents resulted in severe retardation of development (delayed closure of hindgut), caudal and cranial malformation as well as edema in the pericardial and cranial yolk sac region (Fig. 5), and failure to hatch at concentrations of 3.0 and $6.0 \mu \mathrm{M}$. The number of developmentally retarded embryos was significantly increased in eggs exposed to $3.0 \mu \mathrm{M}$ TBBPA and higher, from $23 \mathrm{~h}$ postfertilization (Fisher's exact test: $P=0.01$ ); after $47 \mathrm{~h}$, all embryos exposed to $6.0 \mu \mathrm{M}$ had died. Surviving embryos including controls hatched at $55 \mathrm{~h}$ postfertilization; hatching of normally developing embryos was not delayed.
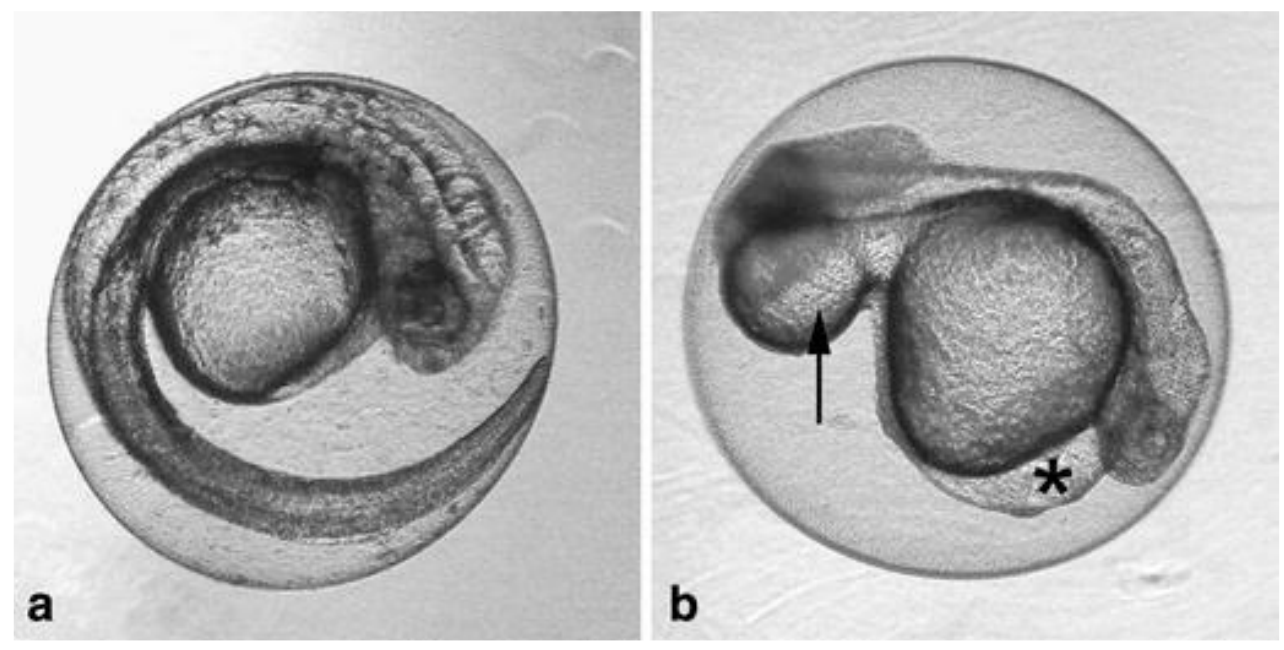

Fig. 5 Embryo of control (a) and exposed (6.0 $\mu \mathrm{M}$ TBBPA; b) zebrafish at $28 \mathrm{~h}$ postfertilization. Note caudal and cranial malformation, delayed closure of hindgut (arrow) and distension of the cranial yolk sac wall (edema; asterisk) in TBBPA-exposed specimen

\section{Juvenile histology}

No dose-related changes were observed in surviving juveniles after 49 days of exposure. Gonad development was sufficient to allow for sex differentiation; only premature gonad tissue was observed. Whereas in all other groups, male differentiation was observed in 50- 
$55 \%$ of the animals, in the $1.5 \mu \mathrm{M}$ group (internal concentration: $5.6 \mu \mathrm{g} / \mathrm{g}$ lipid weight), a statistically significant lower number was found (Fig. 6) and more female gonads were observed (79\%; abundant oocytes of perinucleolar stage). As in adults, thyroid tissue presented moderate activity in all groups; there was no difference in the estimated number of follicles throughout the groups. A striking variation of staining intensity and intracellular vacuolization of liver was noted throughout all groups, which was not dose or gender related.

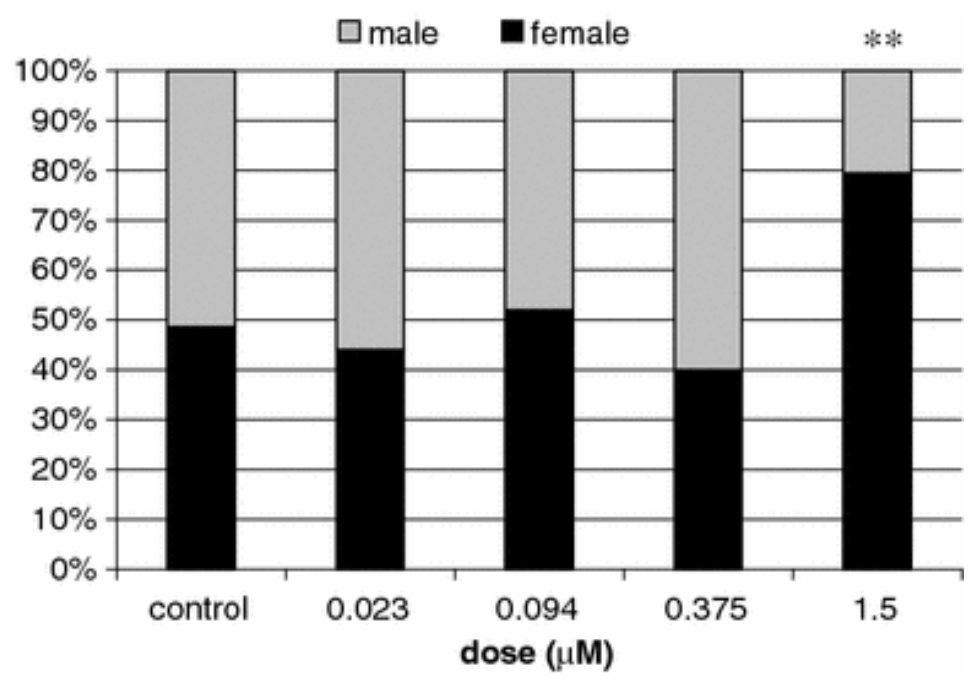

Fig. 6 Development of gender characteristics in gonads from TBBPA-exposed juvenile zebrafish at $47 \mathrm{dph}$. *Significantly different from control $(P<0.01$, Fisher's exact test)

\section{Discussion}

The TBBPA levels in fish were linear to the nominal concentrations (Table 1); the amount of TBBPA recovered from fish represented $<1 \%$ of the total amount offered per fish, indicating minimal bioaccumulative potential of TBBPA in zebrafish. This observation is consistent with the reported short half-life of TBBPA in other fish species (WHO/IPCS 1995; Morris et al. 2004). The absence of a significant difference in TBBPA levels between males and females may indicate that oviposition is not a major route of excretion in zebrafish. The relatively low recovery of TBBPA from fish together with of the dramatic drop of TBBPA water levels during the exposure cycles points to substantial loss of added TBBPA during exposure. Together with the limited decrease of TBBPA levels in aquariums without fish, these data suggest metabolism of the compound by the fish. Major TBBPA metabolites have not been characterized in fish and were beyond the scope of the present study. Methylation of the compound has been described in experimental aquatic exposure; methylated TBBPA is more hydrophobic and as a consequence, bioaccumulation may exceed TBBPA bioaccumulation (Hakk and Letcher 2003). If the animals in the present study accumulated methylated forms as a function of TBBPA exposure, part of the effects discussed below should perhaps be attributed to these metabolites.

The acute effects observed following exposure of adult animals to $3.0 \mu \mathrm{M}$ TBBPA and higher are in agreement with previous observations (Lee et al. 1993). According to Veith and Broderius (1990) baseline toxicity should be considered at these TBBPA concentrations. The high mortality in larvae during the first week of exposure to $1.5 \mu \mathrm{M}$ TBBPA indicates a higher sensitivity to toxic effects of TBBPA compared to older juveniles and adults; accumulation of clear fluid (edema) in the abdominal cavity and pericardial area in developing embryos and larvae exposed to high TBBPA concentrations indicate vascular or osmoregulatory dysfunction.

Although both reduced egg production and hatching indicated a negative effect of TBBPA on reproductive success, a consistent dose-response was only observed for the decreased egg production. Because of the normally abundant and variable egg production in zebrafish, a relatively large critical effect size of 50\% clutch-size reduction was favored for dose-response 
modeling. In a study, where zebrafish were orally exposed to PCBs (Örn et al. 1998), 30-60\% reduced egg production was accompanied by a reduction of mature oocytes in the ovaries.

The relative overrepresentation of immature oocytes and incidental severe oocyte atresia in zebrafish exposed to $1.5 \mu \mathrm{M}$ TBBPA may be consistent with the decreased egg production; there were no indications for a unifying mechanism, particularly since the histological observations were not obviously concentration dependent. Although a reduction in mature oocytes was noted in ovaries of zebrafish exposed to estrogens (Van den Belt et al. 2002; Van der Ven et al. 2003), in the present study there were no indications for an increase of estrogen-dependent production of the yolk precursor VTG (liver-cell morphology and staining properties). Chromatin fragmentation (karyorrhexis) in kidney tubules has been reported as related to estrogen exposure in zebrafish (Olsson et al. 1999). The karyorrhexis observed in this study more likely reflects endogenous estrogen levels than estrogenic activity of TBBPA, since it was restricted to adult females, and there was no relation to TBBPA exposure. Juvenile gonad development may be a more sensitive parameter for estrogenic effects (Brion et al. 2004; Maack and Segner 2004). Presently, female developmental stages predominated at an internal concentration of $5.6 \mu \mathrm{g} \mathrm{TBBPA} / \mathrm{g}$ lipid, a similar level at which the clutch size in adults was reduced. lit remains unclear whether this observation was a result of the preferential development of a female phenotype, or of a higher mortality rate in males. Although the above explanation is favored by the present observation of progressed oocyte development, alternatively, when zebrafish are protogynous (Maack and Segner 2003), the condition may also represent delayed development, consistent with the observed abnormal development during the first week in larvae exposed to $1.5 \mu \mathrm{M}$ and close observation of eggs individually exposed to higher doses. Both delayed development and preferential development of female phenotype have been observed in zebrafish exposed to E2 (Brion et al. 2004). Particularly, in juvenile fish, where plasma estradiol levels can be very low ( $0.3 \mathrm{pmol} / \mathrm{g}$ tissue in juvenile steelhead trout; Yeoh et al. 1996), an internal concentration of $5.6 \mu \mathrm{g} \mathrm{TBBPA} / \mathrm{g}$ lipid (approximately $0.4 \mathrm{nmol} / \mathrm{g}$ wet weight) could have some estrogenic influence. The fact that thyroid hormones are also crucial for the development in fish (Power et al. 2001), and may act synergistically with gonadotropic hormones (Cyr and Eales 1996), hampers interpretation of the present results in mechanistic terms; however, in spite of tentative anti-thyroid effects of TBBPA in tadpoles (Kitamura et al. 2005b), none of the findings in this study were consistent with the effects in zebrafish exposed to the anti-thyroid drug propylthiouracil in a partial life-cycle assay (Van der Ven et al. 2006).

\section{Conclusion}

The present study indicates that exposure of zebrafish to TBBPA can result in effects on population-relevant parameters as egg production, juvenile survival, and gender development of offspring at TBBPA-body burdens around 5-7 $\mu \mathrm{g} / \mathrm{g}$ lipid. In feral fish, levels one order of magnitude lower have been reported. Although the results could be consistent with the estrogenic activity of TBBPA, the extent to which such a mechanism plays a role remains unclear without further supportive evidence. There were no indications for anti-thyroid activity.

Acknowledgment Dr. Wout Slob at RIVM, Bilthoven, is acknowledged for sharing his valuable statistical expertise. The authors thank Bhawani Nagarajah, Helena Priem, and Wil Steenbergen for dedicated histotechnical assistance. This study was carried out in the EUsupported project "Flame-retardants Integrated Risk Assessment" (FIRE), EU contract no. QLK4-CT-2002-00596. 


\section{References}

Arcand-Hoy LD, Benson WH (1998) Fish reproduction: an ecologically relevant indicator of endocrine disruption. Environ Toxicol Chem 17:49-57

Asplund L, Athanasiadou M, Sjödin A, Bergman A, Borjeson H (1999) Organohalogen substances in muscle, egg and blood from healthy Baltic salmon (Salmo salar) and Baltic salmon that produced offspring with the M74 syndrome. Ambio 28:67-76

Birnbaum LS, Staskal DF (2004) Brominated flame retardants: cause for concern. Environ Health Perspect 112:9-17

Brion F, Tyler CR, Pallazi X, Laillet B, Porcher JM, Garric J, Flammarion P (2004) Impacts of 17b-estradiol, including environmentally relevant concentrations, on reproduction after exposure during embryo-larval-, juvenile- and adult-life stages in zebrafish (Danio rerio). Aquat Toxicol 68:193-217

BSEF (2004) Fact sheet on Brominated Flame Retardant TBBPA, Tetrabromobisphenol A. Bromine Science and Environmental Forum. Available from http://www.bsef-site.com.

Christiansen LB, Pedersen KL, Pedersen SN, Korsgaard B, Bjerregaard P (2000) In vivo comparison of xenoestrogens using rainbow trout vitellogenin induction as a screening system. Environ Toxicol Chem 19:18671874

Cyr DG, Eales JG (1996) Interrelationships between thyroidal and reproductive endocrine systems in fish. Rev Fish Biol Fisher 6:165-200

Hakk H, Letcher R (2003) Metabolism in the toxicogenetics and fate of brominated flame retardants-a review. Environ Int 29:801-828

Hamers T, Kamstra J, Sonneveld E, Murk AJ, Zegers BN, Boon JP, Brouwer A (2004) In vitro screening of the endocrine disrupting potency of brominated flameretardants and their metabolites. Organohalogen Compds 66:30163020

Kitamura S, Jinno N, Ohta S, Kuroki H, Fujimoto N (2002) Thyroid hormonal activity of the flame retardants tetrabromobisphenol A and tetrachlorobisphenol A. Biochem Biophys Res Commun 293:554-559

Kitamura S, Suzuki T, Sanoh S, Kohta R, Jinno N, Sugihara K, Yoshihara S, Fujimoto N, Watanabe H, Ohta S (2005a) Comparative study of the endocrine-disrupting activity of bisphenol A and 19 related compounds. Toxicol Sci 84:249-259

Kitamura S, Kato T, lida M, Jinno N, Suzuki T, Ohta S, Fujimoto N, Hanada H, Kashiwagi K, Kashiwagi A (2005b) Anti-thyroid hormonal activity of tetrabromobisphenol A, a flame retardant, and related compounds: Affinity to the mammalian thyroid hormone receptor, and effect on tadpole metamorphosis. Life Sci 76:1589-1601

Körner W, Hanf V, Schuller W, Bartsch H, Zwirner M, Hagenmaier H (1998) Validation and application of a rapid in vitro assay for assessing the estrogenic otency of halogenated phenolic chemicals. Chemosphere 37:2395-2407

Lee SK, Freitag D, Steinberg C, Kettrup A, Kim YH (1993) Effects of dissolved humic materials on acute toxicity of some organic-chemicals to aquatic organisms. Water Res 27:199-204

Maack G, Segner H (2003) Morphological development of the gonads in zebrafish. J Fish Biol 62:895-906

Maack G, Segner H (2004) Life-stage-dependent sensitivity of zebrafish (Danio rerio) to estrogen exposure. Comp Biochem Physiol C 139:47-55

Meerts IATM, van Zanden JJ, Luijks EAC, van Leeuwen-Bol I, Marsh G, Jakobsson E, Bergman Å, Brouwer A (2000) Potent competitive interactions of some brominated flame retardants and related compounds with human transthyretin in vitro. Toxicol Sci 56:95-104

Morris S, Allchin CR, Zegers BN, Haftka JJH, Boon JP, Belpaire C, Leonards PEG, Van Leeuwen SPJ, De Boer J (2004) Distribution and fate of HBCD and TBBPA brominated flame retardants in North Sea estuaries and aquatic food webs. Environ Sci Technol 38:5497-5504

Ohta ST, Okumura T, Nishimura H, Nakao T, Aozasa O, Miyata H (2004) Characterization of Japanese pollution by PBDEs, TBBPA, PCDDs/DFs, PBDDs/DFs and PXDD/DFs observed in the long-term stock-fishes and sediments. BFR 2004, 3rd international workshop on brominated flame retardants, Toronto

Olsen CM, Meussen-Elholm ETM, Samuelsen M, Holme JA, Hongslo JK (2003) Effects of the environmental oestrogens bisphenol A, tetrachlorobisphenol A, tetrabromobisphenol A, 4-hydroxybiphenyl and 4,4'dihydroxybiphenyl on oestrogen receptor binding, cell proliferation and regulation of oestrogen sensitive proteins in the human breast cancer cell line MCF-7. Pharmacol Toxicol 92:180-188

Olsson P, Westerlund L, Teh SJ, Billsson K, Berg AH, Tysklind M, Nilsson J, Eriksson L, Hinton DE (1999) Effects of maternal exposure to estrogen and PCB on different life stages of zebrafish (Danio rerio). Ambio 28:100-106 
Örn S, Andersson PL, Förlin L, Tysklind M, Norrgren L (1998) The impact on reproduction of an orally administered mixture of selected PCBs in zebrafish (Danio rerio). Arch Environ Contam Toxicol 35:52-57

Osako M, Kim YJ, Sakai SI (2004) Leaching of brominated flame retardants in leachate from landfills in Japan. Chemosphere 57:1571-1579

Power DM, Llewellyn L, Faustino M, Nowell MA, Bjornsson BT, Einarsdottir IE, Canario AVM, Sweeney GE (2001) Thyroid hormones in growth and development of fish. Comp Biochem Physiol C 130:447-459

Ronisz D, Finne EF, Karlsson H, Forlin L (2004) Effects of the brominated flame retardants hexabromocyclododecane (HBCDD), and tetrabromobisphenol A (TBBPA), on hepatic enzymes and other biomarkers in juvenile rainbow trout and feral eelpout. Aquat Toxicol 69:229-245

Sellström U, Jansson B (1995) Analysis of tetrabromobisphenol A in a product an environmental samples. Chemosphere 31:3085-3092

Slob W (2002) Dose response modeling of continuous endpoints. Toxicol Sci 66:298-312

Van den Belt K, Wester PW, Van der Ven LTM, Verheyen R, Witters H (2002) Effects of ethynylestradiol on the reproductive physiology in zebrafish (Danio rerio): time dependency and reversibility. Environ Sci Technol 21:767775

Van der Ven LTM, Wester PW, Vos JG (2003) Histopathology as a tool for the evaluation of endocrine disruption in zebrafish (Danio rerio). Environ Toxicol Chem 22:908-913

Van der Ven LTM, Van den Brandhof E-J, Vos JH, Power DM, Wester PW (2006) Effects of the antithyroid agent propylthiouracil in a partial life cycle assay with zebrafish. Environ Sci Technol 40:74-81

Veith GD, Broderius SJ (1990) Rules for distinguishing toxicants that cause types I and II narcosis syndromes. Environ Health Perspect 87:207-211

Watanabe I, Sakai S (2003) Environmental release and behavior of brominated flame retardants. Environ Int 29:665682

WHO/IPCS (1995) Environmental health criteria 172: tetrabromobisphenol A and derivatives. World Health Organization, Geneva, Switzerland

Yeoh CG, Schreck CB, Feist GW, Fitzpatrick MS (1996) Endogenous steroid metabolism is indicated by fluctuations of endogenous steroid and steroid glucuronide levels in early development of the steelhead trout (oncorhynchus mykiss). Gen Comp Endocrinol 103:107-114 